\title{
Multiple Micronutrient Supplementation Effect on Vital Metabolic parameters of Stable HIV Patients on Long term Highly Active Antiretroviral Therapy; A Randomized Crossover Trial
}

\author{
Anthony C. Iwu', Kenechi A. Uwakwe' ${ }^{1}$, Chukwuma B. Duru' ${ }^{2}$, Kevin C. Diwe2, \\ Irene A. Merenu ${ }^{2}$, Abah O. Steve ${ }^{4}$, Christopher N. Obionu ${ }^{3}$, Nathan C. Nwaimo ${ }^{5}$, \\ Uche R. Oluoha ${ }^{1}$, Ikechi Ohanle ${ }^{1}$ and Emmanuel U. Ndukwu ${ }^{1}$ \\ ${ }^{1}$ Department of Community Medicine, Imo State University Teaching Hospital, \\ Orlu Imo State, Nigeria \\ ${ }^{2}$ Department of Community Medicine, Imo State University, Owerri, Imo State, Nigeria \\ ${ }^{3}$ College of Medicine, University of Nigeria Nsukka, Enugu State, Nigeria \\ ${ }^{4}$ College of Medicine, Ambrose Ali University Ekpoma, Edo Nigeria \\ ${ }^{5}$ Department of Chemical Pathology, Imo State University Teaching Hospital, \\ Orlu Imo State, Nigeria \\ *Corresponding author
}

\begin{abstract}
A B S T R A C T
Keywords

Micronutrient

Supplementation,

Vital metabolic

parameters,

HIV patients,

HAART.

Article Info

Accepted:

20 February 2016

Available Online:

10 March 2016

The effective and widespread use of Highly Active Antiretroviral Therapy (HAART) has resulted in people with Human Immunodeficiency Virus (HIV) infection now living longer especially in resource limited regions with non AIDS defining diseases becoming a major cause of illness and management concern in patients on long term HAART. To determine the effect of multiple micronutrient supplementation on the vital metabolic parameters of clinically stable HIV patients on long term HAART. A randomized crossover intervention trial was used to determine the effect of a 12 week daily consumption of multiple micronutrient supplements on 50 clinically stable HIV infected clients receiving treatment from the Imo State University Teaching Hospital. The participants were purposively selected based on certain inclusion criteria and were randomized into two groups to receive the supplement at different periods after a washout period. The measurements of the levels of the metabolic parameters were taken at baseline, 12, 20 and 32 weeks. The mean age of the participants studied was $43.8 \pm 10.8$ years with an average duration on HAART of $3.2 \pm 1.5$ years. At baseline, $55.3 \%$ of the participants were severely immunodeficient, $51.1 \%$ were either overweight or obese, $45 \%$ were hypertensive and $57.4 \%, 55.3 \%, 80.9 \%$ and $68.1 \%$ respectively had high serum urea, albumin and liver enzymes. The intervention result, revealed that there was no statistically significant difference in the levels of the vital metabolic parameters with micronutrient supplementation compared to no supplementation. Micronutrient supplementation in HIV patients on long term HAART appear not to have any significant effect on the vital metabolic parameters.
\end{abstract}




\section{Introduction}

The effective and widespread use of HAART has resulted in people with HIV infection now living longer as HAART alone has been associated with the halting of the devastation and rapid progression of the disease due to immunodeficiency, wasting, metabolic disorders and nutrient deficiencies (Beach et al., 1992; Montaner et al., 1998).

The clinical consequences of effective and widespread use of HAART has been longer survival and improved quality of life of HIV infected patients with the emergence of non AIDS defining illnesses such as malignancies, cardiovascular, renal, hepatic and other related disorders with its associated abnormal levels of metabolic parameters (Montaner et al., 1998; Walensky et al.; Wester et al., 2011).

The risk of developing non AIDS defining illnesses in HIV patients on long term HAART especially resource poor countries is increasing as more people are now on HAART for longer periods as is the case in the developed countries where treatment with HAART began since 1996 (Panel on Antiretroviral Guidelines for Adults and Adolescents). A Swiss Cohort study observed that while the incidences of AIDS defining events are reducing, the non AIDS defining events are increasing with aging and as a consequence, the non AIDS related diseases are now becoming major causes of health concern in HIV patients on long term HAART with associated morbidity and mortality [Hasse et al., 2011; The Antiretroviral Therapy Cohort Collaboration (ART-CC writing committee); 2010]. This particularly appears to be constituting a significant problem in sub Saharan Africa and therefore requires that monitoring, prevention and treatment should be a critical component of care in resource limited regions (Wester et al., 2011).
Nutritionappears to play a role in the development of non AIDS defining illnesses in HIV patients on long term HAART as a study by Wester et al. (Wester et al., 2011) reported an increased incidence of non AIDS defining illnesses in an African Cohort especially among the overweight adults. With HIV and nutrition being strongly related, the nutritional implications in the prognosis and management of HIV infection especially in developing countries is highlighted by the associated prevalence of nutrient deficiencies established early in the course of HIV infection coupled with the fact that micronutrient deficiencies are more likely to occur among residents of developing countries like Nigeria; that is ranked the $3^{\text {rd }}$ highest with respect to absolute numbers of stunting with annual losses of US $\$ 1.5$ billion in Gross Domestic Product due to vitamins and mineral deficiencies (Montaner et al., 1998; United Nations Children's Fund (UNICEF),2009; World Bank; Jiang et al., 2012).

It has been established that HIV infection can lead to micronutrient deficiencies and these micronutrient deficiencies may persist in these patients on long term HAART which may in turn affect the absorption, pharmacokinetics and hence toxicity of HAART thereby influencing the levels of their vital metabolic parameters; even though it has been reported that the initiation of HAART may improve some of these deficiencies observed in these patients (Keusch, 1990; Raiten et al., 2005).

Similarly, it has been observed that HIV patients on long term HAART have improved nutritional states probably from diet, even though it has also been observed that most of the protective effects of micronutrient consumption were due to intake of supplements rather than diet whichwas correlated to its ability to decrease 
oxidative damages and enhance immunity (Baum et al., 2013). Furthermore, it has been suggested that micronutrient supplementation may play a role in reducing mitochondrial dysfunction, oxidative stress and metabolic complications which are commonly experienced by HIV patients receiving HAART (Drain et al., 2007).

\section{Methodology}

\section{Study Area}

The study was conducted at the adult HIV clinic of Imo State University Teaching Hospital situated in Orlu Local Government Area (LGA) of Imo State, South East, Nigeria. The study area is predominantly rural with a population density varying from 230-1400 persons per sq. $\mathrm{km}$. The HIV clinic has a total enrolment of 4769 patientsand offers comprehensive outpatient HIV care services to about 900 patients monthly, comprising those residing within and outside the State (Iwu et al., 2016).

\section{Study Population}

The study population comprised of adult HIV infected patients accessing HAART from the HIV clinic who were either on the first or second line drug regimen consisting of Zidovudine, Lamuvidine, Emtricitabine, Tenofovir, Abacavir Nevirapine, Efavirenz, Atazanavir and Lopinavir/Ritonavir.

\section{Study Design}

The study design was a randomized single blinded controlled AB/BA crossover interventional trial. The study participants were randomized into two groups $\mathrm{AB}$ and BA. The $\mathrm{AB}$ received micronutrient supplement and BA received no supplement in the first intervention period (0-12 weeks), following a washout period of 8 weeks, the groups were crossed over with the BA group subsequently receiving micronutrient supplement and $\mathrm{AB}$ receiving no supplement in the second intervention period (20-32 weeks).

\section{Study Intervention Product}

The study intervention product was a multiple micronutrient supplement which is commercially available as Immunance tablets and developed by Meyer/Vitabiotics of Meyer health care PVT Ltd. The tablets were taken once daily for 12 weeks. Drug constituents are shown below;

\section{Sample Size/Sample Technique}

The minimum sample size of 15 participants per group was calculated using the approximate approach and in anticipation of a possible significant carryover effect which may necessitate the setting aside of the second treatment period data in order to analyse only the first treatment period; the researchers increased the total number of participants in the study to 50 to accommodate this possibility. The fifty participants were selected using purposive sampling technique based on certain inclusion and exclusion criteria but 3 participants were lost to follow up ( $\mathrm{AB}$ group=25and BA group=22).

\section{Selection Criteria}

The selection criteria were based on the following; having CD4 T cell counts of 350 cells/ul or less, receiving HAART for at least one year, with a minimum clinic attendance of $95 \%$ and were clinically stable i.e. having no fever, diarrhoea or cough. Patients on current or previous micronutrient supplement use within the last three months, pregnant women or women intending to get pregnant, breastfeeding mothers were excluded from the study. 


\section{Clinical/Laboratory Measurements}

All clinical measurements such as weight, height and blood pressure were done using standard measurement scales and blood pressure apparatus by the nursing officers. The laboratory measurements of the metabolic parameters which included serum cholesterol, serum albumin, serum creatinine, serum urea, serum alkaline phosphatase, random blood sugar and liver enzymes i.e.serum glutamic oxaloacetic transaminase (SGOT)and serum glutamicpyruvic transaminase (SGPT) were done by the principal medical laboratory scientist and assisted by medical laboratory technicians using Randox diagnostic reagent Kits. The laboratory established its own reference range with guidance of the Randox kit expected normal values to reflect the age, sex, diet and geographical location of the population. Laboratory reference for normal values as shown in Figure 2.

\section{Data Analysis}

The data collected from the AB/BA groups were analysed with SPSS version 20 and compared using Independent sample t test with a two sided hypothesis and a p-value set at 0.05 . In analysing the intervention effect on metabolic parameters, the mean of the within subject differences of the levels of the particular metabolic parameter of the $\mathrm{AB}$ group at 12 and 32 weeks were compared with the mean of the within subject differences of thatmetabolic parameter of the BA group at 12 and 32 weeks. In analysing for carryover effects, the mean of the within subject sums of the levels of the particular metabolic parameterof the $\mathrm{AB}$ group at 12 and 32 weeks were compared with the mean of the within subject sums of that metabolic parameter of the BA group at 12 and 32 weeks.

\section{Ethical Approval}

Ethical approval was obtained from the Ethics Committee of Imo State University Teaching Hospital (IMSUTHEC) and written informed consents were obtained from the participants. All authors hereby declare that the study has therefore been performed in accordance with the ethical standards laid down in the 1964 Declaration of Helsinki.

\section{Limitations of Study}

The study assessed the effect of multiple micronutrient supplementation in clinically stable HIV patients on long term HAART and not on HAART naïve patients with obvious signs and symptoms of acute disease. Furthermore, the sample size determination was based on achieving a minimum treatment difference of 12 cells $/ \mathrm{mm}^{3}$ in the levels of CD4 T Cell count. Based on these, caution should be taken in generalizing the findings of this work.

\section{Results and Discussion}

Fifty participants were recruited to the study but three participants dropped out from the study after randomization with the $\mathrm{AB}$ and BA groups having 25 and 22 participants respectively. The two groups were similar with respect to their socio-demographic characteristics. More than half of the participants were females $(55.7 \%)$, married $(53.2 \%)$ and were traders $(57.4 \%)$ with majority of the participants (70.3\%) being within the ages of 30-49 years old and having either a primary or secondary school education as their highest level of educational status (89.4\%). The average number of years the participants were on HAART was $3.2 \pm 1.3$ years with the majority $(85.1 \%)$ receiving Zidovudine, Lamivudine and Nevirapine combination therapy. There was no statistically 
significant difference in socio-demographic characteristics of the groups, $\mathrm{p}>0.05$. Table 1 .

At baseline the two groups were similar with respect to $\mathrm{CD} 4 \mathrm{~T}$ cell counts, Body Mass Index and Blood Pressure measurements. More than half of the participants were severely immunodeficient, $(55.3 \%)$ and were either overweight or obese, $(51.1 \%)$. About $44.7 \%$ of the participants had high blood pressure measurements (Table 2).

The two groups $\mathrm{AB}$ and $\mathrm{BA}$ were similar with respect to the baseline vital metabolic parameters ( $>0.05)$ except for serum cholesterol levels $(p=0.005)$. At baseline, more than three quarters of the participants had normal serum cholesterol levels (87.2\%), normal serum creatinine levels $(93.6 \%)$ and high serum GOT levels $(80.9 \%)$ with more than half of the participants having high serum albumin levels (55.3\%), high serum GPT levels $(68.1 \%)$, high serum urea levels $(57.4 \%)$ and normal random blood sugar levels $(55.3 \%)$. Table 3.

At 12 weeks after supplementation of the $\mathrm{AB}$ group, there was no statistical significant difference in each of the following mean metabolic parameters (serum GPT, GOT, Alkaline Phosphatase, Albumin) between the $\mathrm{AB}$ and BA groups. ( $>0.05$ ) At 32 weeks after supplementation of the BA group, there was no statistical significant difference in each of the mean metabolic parameters (serum GPT, GOT, Alkaline Phosphatase, Albumin)between the $\mathrm{AB}$ and $\mathrm{BA}$ groups. ( $>0.05)$ Overall, the mean ofwithin subject differences between the $12^{\text {th }}$ and $32^{\text {nd }}$ week for each metabolic parameter of the $A B$ group did not differ significantly from the mean of within subject differences of the BA group of the corresponding metabolic parameter. $(p>0.05)$ Also the within subject sums between the $12^{\text {th }}$ and $32^{\text {nd }}$ week of the ABgroup for each metabolic parameter did not differ significantly from the within subject sums of the corresponding metabolic parameter in the BA group. $(\mathrm{p}=0.05)$. Table 4.

At 12 weeks after supplementation of the $\mathrm{AB}$ group, there was no statistical significant difference in each of the following mean metabolic parameters (serum Cholesterol, Urea, Creatinine and Random blood sugar) between the $\mathrm{AB}$ and BA groups. (p>0.05) At 32 weeks after supplementation of the BA group, there was no statistical significant difference in each of the mean metabolic parameters (serum Cholesterol, Urea, Creatinine and Random blood sugar) between the $\mathrm{AB}$ and $\mathrm{BA}$ groups. ( $p>0.05$ ) Overall, the mean of within subject differences between the $12^{\text {th }}$ and $32^{\text {nd }}$ week for each metabolic parameter of the $\mathrm{AB}$ group did not differ significantly from the mean of within subject differences of the BA group of the corresponding metabolic parameter. ( $p>0.05)$ Also the within subject sums between the $12^{\text {th }}$ and $32^{\text {nd }}$ week of the $\mathrm{AB}$ group for each metabolic parameter did not differ significantly from the within subject sums of the corresponding metabolic parameter in the BA group. $(\mathrm{p}=0.05)$. Table 5.

Using the analytical approach of crossover designs based on the publication by Wellek et $a l,{ }^{17}$ the results suggest that multiple micronutrient supplementation did not have any statistically significant effect on the levels of the vital metabolic parameters (serum cholesterol, serum albumin, serum creatinine, serum urea, serum alkaline phosphatase, random blood sugar, SGOT and SGPT) in HIV patients on long term HAART. According to Wellek et al., the consideration is that the two randomized groups within the sample are independent since each group receives supplementation at different intervention periods i.e. $0-12^{\text {th }}$ week for the $A B$ group and $20^{\text {th }}-32^{\text {nd }}$ week 
for the BA group after a washout period. This results inone group receiving supplements while the other group does not receive any supplementin that particular intervention period. So in effect the participants who received supplements in the first intervention period, did not receive in the second intervention period and the group means (AB, BA) of the differences (within subject differences) in the levels of the metabolic parameters for each participant between the $12^{\text {th }}$ and $32^{\text {nd }}$ week were compared.

Table.1 Distribution of Sociodemographic Characteristics

Table 1: Distribution of Sociodemographic Characteristics

\begin{tabular}{|c|c|c|c|c|c|c|}
\hline & $\begin{array}{l}\text { B Grp } \\
\text { n=25) } \\
\text { Freq }\end{array}$ & $\begin{array}{l}\text { B-A Grp } \\
(\mathrm{n}=22) \\
\text { Freq }\end{array}$ & Total $(\%)$ & ) Statistic & $\mathrm{df}$ & p-value \\
\hline Age(Yrs) & & & & & & \\
\hline $30-39$ & 9 & 11 & $20(42.6)$ & $\mathrm{t}=1.96$ & 45 & 0.057 \\
\hline $40-49$ & 6 & 7 & $13(27.7)$ & & & \\
\hline $50-59$ & 4 & 3 & $7(14.9)$ & & & \\
\hline $60-69$ & 6 & 1 & $7(14.9)$ & & & \\
\hline $\mathrm{X} \pm \mathrm{SD} 46$ & $6.6 \pm 11.5$ & $40.6 \pm 9.1$ & $43.8 \pm 10.8$ & & & \\
\hline Gender & & & & & & \\
\hline Male & 12 & 9 & $21(44.7)$ & $\chi^{2}=0.24$ & +1 & 0.626 \\
\hline Female & 13 & 13 & $26(55.3)$ & & & \\
\hline Occupatio & & & & & & \\
\hline Trading & 13 & 14 & $27(57.4)$ & $\chi^{2}=0.88$ & 3 & $0.831^{*}$ \\
\hline Business & 74 & $11(23$ & 3.4) & & & \\
\hline Artisan & 3 & 2 & $5(10.6)$ & & & \\
\hline Civil & & & & & & \\
\hline Servant & 2 & 2 & $4(8.5)$ & & & \\
\hline MaritalSt & tatus & & & & & \\
\hline Single & 1 & 6 & $7(14.9)$ & $\chi 2=5.38$ & 2 & $0.068 *$ \\
\hline Married & 15 & 102 & $25(53.2)$ & & & \\
\hline Separated & 9 & $\begin{array}{ll}6 & 1\end{array}$ & $15(31.9)$ & & & \\
\hline Education & & & & & & \\
\hline Primary & 14 & 72 & $21(44.7) \gamma$ & $\chi^{2}=3.59$ & 1 & $0.166^{*}$ \\
\hline Secondary & 8 & 13 & $21(44.7)$ & & & \\
\hline Tertiary & 3 & 2 & $5(10.6)$ & & & \\
\hline Years HA & ART & & & & & \\
\hline $1-2$ & 11 & 8 & 19(40.4) & $\mathrm{t}=1.25$ & 45 & 0.218 \\
\hline $3-4$ & 11 & 7 & 18(38.3) & & & \\
\hline $5-6$ & 3 & 7 & $10(21.3)$ & & & \\
\hline $\mathrm{X} \pm \mathrm{SD}$ & $3.0 \pm 1.3$ & $\begin{array}{ll}3 & 3.5 \pm 1.7\end{array}$ & $73.2 \pm 1.5$ & & & \\
\hline
\end{tabular}

*Likelihood ratio used when $>\mathbf{2 0} \%$ cells have expected values $<5$

Table.2 Distribution of Baseline CD4 and Physical Parameters

\begin{tabular}{|c|c|c|c|c|c|c|}
\hline & $\begin{array}{c}\begin{array}{c}\text { A-B Grp } \\
(\mathrm{n}=25) \\
\text { Freq }\end{array} \\
\end{array}$ & $\begin{array}{l}\begin{array}{l}\text { B-A Grp } \\
(\mathrm{n}=22)\end{array} \\
\text { Freq }\end{array}$ & $\operatorname{Total}(\%)$ & Statistic & df & p-value \\
\hline \multicolumn{7}{|l|}{$\begin{array}{l}\mathrm{CD}^{(1)} \\
\text { cells/ul }\end{array}$} \\
\hline $\begin{array}{l}\leq 350>200 \\
\leq 20014\end{array}$ & $\begin{array}{ll}0 & 11 \\
& \end{array}$ & $\begin{array}{l}10 \\
26(55.3)\end{array}$ & $21(44.7)$ & $\mathrm{t}=0.93$ & 36 & 0.360 \\
\hline $\mathrm{X} \pm \mathrm{SD}$ & $182.4 \pm 63.6$ & $204.8 \pm 96.6$ & $192.9 \pm 80.6$ & & & \\
\hline \multicolumn{7}{|c|}{ Blood Pressure $^{(2)}$} \\
\hline $\begin{array}{l}\text { Normal } \\
\text { High }\end{array}$ & $\begin{array}{l}14 \\
11\end{array}$ & $\begin{array}{l}12 \\
10\end{array}$ & $\begin{array}{l}26(55.3) \\
21(44.7)\end{array}$ & $\chi 2=0.01$ & 1 & 0.920 \\
\hline \multicolumn{7}{|c|}{$\mathrm{BMI}^{(3)} \mathrm{kg} / \mathrm{m}^{2}$} \\
\hline $\begin{array}{l}18.5-25.0 \\
>25-29.9 \\
>30 \\
X \pm \text { SD }\end{array}$ & $\begin{array}{c}14 \\
7 \\
4 \\
24.8 \pm 4.3\end{array}$ & $\begin{array}{c}9 \\
10 \\
3 \\
25.2 \pm 3.9\end{array}$ & $\begin{array}{c}23(48.9) \\
17(36.2) \\
7(14.9) \\
25.0 \pm 4.1\end{array}$ & $t=2.95$ & 45 & 0.769 \\
\hline
\end{tabular}

(1) Advanced Immunodeficiency- CD4 T cells $\leq 350$ but $>200 \mathrm{~mm}^{3}$, Severe Immunodeficiency-CD4 T cells $\leq 200 \mathrm{~mm}^{3}$ (2) Systolic and Diastolic taken into account (3) Normal BMI- $18.5-25.0 \mathrm{~kg} / \mathrm{m}^{2}$ 
Table.3 Distribution of Baseline Vital Metabolic Parameters

Table 3 Distribution of baseline Vital Metabolic Parameters

\begin{tabular}{|c|c|c|c|c|c|c|c|}
\hline \multirow{6}{*}{ Cholesterol } & \multirow{2}{*}{\multicolumn{2}{|c|}{$\begin{array}{c}\text { A-B Grp(n=25) } \\
\text { Freq }\end{array}$}} & \multicolumn{5}{|l|}{ B-A Grp $(n=22)$} \\
\hline & & & Freq & $\operatorname{Total}(\%)$ & Statistic & df & pvalue \\
\hline & Low & 4 & 1 & $5(10.6)$ & $\mathrm{t}=2.93$ & 45 & 0.005 \\
\hline & Normal & 21 & 20 & $41(87.2)$ & & & \\
\hline & High & 0 & 1 & $5(2.1)$ & & & \\
\hline & Mean \pm SD & $3.3 \pm 0.8$ & $4.1 \pm 1.1$ & $3.6 \pm 1.0$ & & & \\
\hline \multirow[t]{4}{*}{$\overline{\text { Albumin }}$} & Low & 2 & 2 & $4(8.5)$ & $\mathrm{t}=0.05$ & 45 & 0.963 \\
\hline & Normal & 11 & 6 & $17(36.2)$ & & & \\
\hline & High & 12 & 14 & $26(55.3)$ & & & \\
\hline & Mean \pm SD & $42.9 \pm 4.3$ & $42.8 \pm 4.7$ & $42.9 \pm 4.4$ & & & \\
\hline \multirow[t]{3}{*}{ Alk Phos } & Normal & 19 & 15 & $34(72.3)$ & $\mathrm{t}=0.27$ & 45 & 0.786 \\
\hline & High & 6 & 7 & $13(27.7)$ & & & \\
\hline & Mean \pm SD & $30.2 \pm 12.4$ & $31.1 \pm 10.9$ & $30.6 \pm 11.6$ & & & \\
\hline \multirow[t]{3}{*}{ Serum GOT } & Normal & 5 & 4 & $9(19.1)$ & $\mathrm{t}=1.85$ & 45 & 0.071 \\
\hline & High & 20 & 18 & $38(80.9)$ & & & \\
\hline & Mean \pm SD & $22.0 \pm 12.7$ & $31.3 \pm 21.4$ & $26.3 \pm 17.7$ & & & \\
\hline \multirow[t]{3}{*}{ Serum GPT } & Normal & 8 & 7 & $15(31.9)$ & $\mathrm{t}=0.72$ & 45 & 0.478 \\
\hline & High & 17 & 15 & $32(68.1)$ & & & \\
\hline & Mean \pm SD & $18.8 \pm 9.8$ & $21.1 \pm 12.6$ & $19.9 \pm 11.1$ & & & \\
\hline \multirow[t]{4}{*}{ Serum Urea } & Low & 0 & 3 & $3(6.4)$ & $\mathrm{t}=0.59$ & 45 & 0.556 \\
\hline & Normal & 12 & 5 & $17(36.2)$ & & & \\
\hline & High & 13 & 14 & $27(57.4)$ & & & \\
\hline & Mean \pm SD & $7.6 \pm 3.4$ & $8.3 \pm 4.6$ & $7.9 \pm 4.0$ & & & \\
\hline \multirow[t]{3}{*}{ Serum Creat } & Normal & 23 & 21 & $44(93.6)$ & $\mathrm{t}=0.49$ & 45 & 0.625 \\
\hline & High & 2 & 1 & $3(6.4)$ & & & \\
\hline & Mean \pm SD & $86.1 \pm 30.2$ & $81.9 \pm 28.3$ & $84.1 \pm 29.1$ & & & \\
\hline \multirow[t]{4}{*}{ R Bld Sugar } & Low & 8 & 12 & $20(42.6)$ & $\mathrm{t}=0.25$ & 34 & 0.807 \\
\hline & Normal & 17 & 9 & $26(55.3)$ & & & \\
\hline & High & 0 & 1 & $1(2.1)$ & & & \\
\hline & Mean \pm SD & $3.8 \pm 1.3$ & $3.7 \pm 2.1$ & $3.8 \pm 1.7$ & & & \\
\hline
\end{tabular}

Table.4 Distribution of Mean Serumlevels of GPT, GOT, Alkaline Phosphatase, Albumin

Table 4 Distribution of mean serumlevels of GPT, GOT, Alkaline phosphatase, Albumin

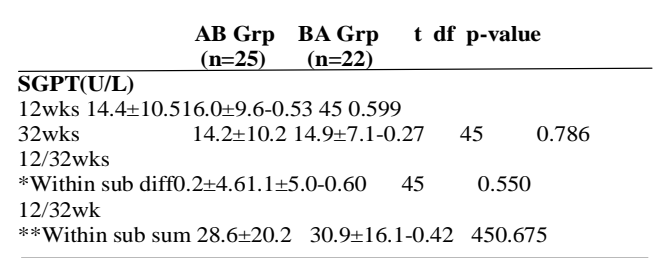

W*Within sub sum $28.6 \pm 20.2 \quad 30.9 \pm 16.1-0.42 \quad 450.675$

\section{SGOT(U/L)}

12 wks $18.3 \pm 12.023 .1 \pm 13.5-1.27450 .210$

$32 \mathrm{wks} \quad 18.0 \pm 10.120 .9 \pm 11.4-0.90 \quad 45 \quad 0.372$

$12 / 32$ wks

$+5.42 .2 \pm 5.9-1.1545 \quad 0.256$

12/32wks

**Within sub sum $36.4+21.443 .9+24.3 \quad-1.13 \quad 45 \quad 0.264$

Alka phos(IU/L)

12 wks $23.1 \pm 7.525 .4 \pm 6.7-1.12450 .268$

$32 \mathrm{wks} \quad 24.5 \pm 6.725,5 \pm 6.6-0.5045 \quad 0.617$

$12 / 32$ wks

*Within sub diff-1.4 $\pm 5.1-0.09 \pm 7.7-0.72 \quad 45 \quad 0.475$

$12 / 32$ wks

**Within sub sum 47.6 $\pm 13.2 \quad 50.9 \pm 10.9-0.93450 .358$

$\operatorname{Albumin}(\mathbf{g} / \mathbf{L})$

12wks 38.0 $\pm 2.837 .6 \pm 2.3 \quad 0.4345 \quad 0.670$

32 wks $\quad 39.2 \pm 1.939 .1 \pm 2.0 \quad 0.18450 .857$

$12 / 32$ wks

*Within sub diff $\quad-1.3 \pm 3.3-1.5 \pm 2.70 .25 \quad 45 \quad 0.804$

$12 / 32 \mathrm{wks}$

**Within sub sum $\quad 77.2 \pm 3.5 \quad 76.7 \pm 3.4 \quad 0.42 \quad 450.674$

*Within sub diff- The group mean of the individual participant

measurement difference of the $12^{\text {th }}$ and $32^{\text {nd }}$ week

**Within sub sum- The group mean of the individual participant measurement sum of the $12^{\text {th }}$ and $32^{\text {nd }}$ week 
Table.5 Distribution of Mean Serum Levels of Cholesterol, Urea, Creatinine and Random Blood Sugar

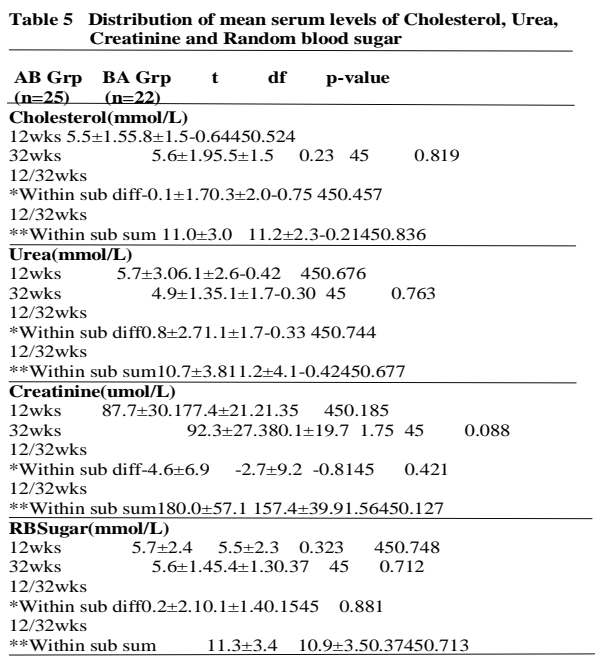

*Within sub diff- The group mean of the individual participant measurement difference of the $12^{\text {th }}$ and $32^{\text {nd }}$ week **Within sub sum- The group mean of the individual participant measurement sum of the $12^{\text {th }}$ and $32^{\text {nd }}$ week

Fig.2 Laboratory Reference for Normal Values

\begin{tabular}{|c|c|}
\hline Nutritional Information & Average per tablet \\
\hline Vitamin A & $5000 \pi$ \\
\hline Vitamin D3 & $800 \mathrm{U}$ \\
\hline Vitamin E & $25 \mathrm{mg}$ \\
\hline Vitamin K & $90 \mu g$ \\
\hline Vitamin C & $150 \mathrm{mg}$ \\
\hline Vitamin BI (Thiamine) & $10 \mathrm{mg}$ \\
\hline Vitamin B2 (Riboflavin) & $7.5 \mathrm{mg}$ \\
\hline Vitamin B6 & $3 \mathrm{mg}$ \\
\hline Folic Acid & $1500 \mu \mathrm{g}$ \\
\hline Vitamin B12 & $15 \mu \mathrm{g}$ \\
\hline Iron & $10 \mathrm{mg}$ \\
\hline Magnesium & $100 \mathrm{mg}$ \\
\hline Zinc & $15 \mathrm{mg}$ \\
\hline Iodine & $150 \mu \mathrm{g}$ \\
\hline Copper & $1.5 \mathrm{mg}$ \\
\hline Manganese & $4 \mathrm{mg}$ \\
\hline Selenium & $200 \mu g$ \\
\hline Chromium & $75 \mu \mathrm{g}$ \\
\hline L-Cystine & $33 \mathrm{mg}$ \\
\hline L-Carnitine & $30 \mathrm{mg}$ \\
\hline Calcium pentithenate & $20 \mathrm{mg}$ \\
\hline Betacarotene(NaturalCarotenoid. & $50 \mathrm{mg}$ \\
\hline
\end{tabular}




$\begin{array}{lr}\text { Metabolic Parameter } & \begin{array}{r}\text { Normal Values } \\ \text { Serum GPT }\end{array} \\ \text { Serum G0T } & <12 \mathrm{U} / \mathrm{L} \\ \text { Serum Alkaline phosphatase } & 9-32 \mathrm{U} / \mathrm{L} \\ \text { Serum Cholesterol } & 2.6-6.0 \mathrm{mmol} / \mathrm{L} \\ \text { Serum Urea } & 2.6-6.0 \mathrm{mmol} / \mathrm{L} \\ \text { Serum Creatinine } & 44-133 \mu \mathrm{mol} / \mathrm{L} \\ \text { Serum Albumin } & 38-42 \mathrm{~g} / \mathrm{L} \\ \text { Random Blood Sugar } & 3.3-8.3 \mathrm{mmol} / \mathrm{L}\end{array}$

Furthermore, in probable supportfor the result showing a lack of statistical significant effect on the metabolic parameters to the extent of the limitation of the power of this study, it was observed that in the first intervention period where the $A B$ group received supplementation and the BA group did not receive supplementation, there was no statistically significant difference between the mean levels of the $\mathrm{AB}$ and $\mathrm{BA}$ groups for any of the metabolic parameters. Similarly, in the second intervention period where BA group now received supplementation and the $\mathrm{AB}$ group did not receive supplementation after a washout period, it was observed that there was no statistically significant difference between the mean levels of the $\mathrm{BA}$ and $\mathrm{AB}$ groups for any of the metabolic parameters.

The introduction and adherence to HAART for relatively long periods appeared to have influenced the nutritional states of the participants in this study as none of the participants at baseline had a BMI of less than $18 \mathrm{~kg} / \mathrm{m}^{2}$. This is supported by some earlier studies that reported, that under nutrition which was a common state among HIV patients in the pre HAART era is now gradually shifting towards improved nutritional states in the post HAART era. ${ }^{\mathbf{1 8 , 1 9}}$ Further to this, Drain et al., also suggested that HAART initiation may improve some nutrient deficiencies seen in HIV patients and these observations may explain a lack of significant effect of micronutrient supplementation on the metabolic parameters in these patients who have been on HAART for relatively long periods.

It was generally observed at baseline, that more than $50 \%$ of the participants had normal serum levels of Cholesterol, Alkaline Phosphatase, Creatinine and Random blood sugar and more than 50\% had high serum levels of Albumin, Urea, SGOT and SGPT. More specifically with respect to some of the metabolic parameters, Riddler et al. (2003) noted that HIV infection before treatment resulted in substantial decreases in serum cholesterol levels and upon HAART initiation was associated with increases in total cholesterol levels. Lucien et al. (2010) also reported that increases in SGOT levels were associated with SGPT levels upon treatment and treatment duration and furthermore, Alo et al. (2012) reported that high levels of serum creatinine and similarly high levels of serum urea were associated with the use of antiretroviral therapy.

All this further highlights the need for more studies on the metabolic parameters in HIV patients on long term HAART especially in resource limited regions where more people in these regions are now using and adhering to HAART for longer periods. In HIV patients using and adhering to long term HAART, the use micronutrient supplementation may be limited as these patients are now being associated with improved nutritional states and therefore 
generally appear not to benefit from supplementation but rather proper and adequate dietary nutrition.

\section{Acknowledgement}

We thank the patients that agreed to participate in this research despite all the challenges, the research assistants who helped during the data collection and the entire staff of the HIV clinic of the hospital for their cooperation.

\section{References}

Beach, R.S., Mantero-Atienza, E., ShorPosner, G., Javier, J.J., Szapocznik, J., Morgan, R., et al. 1992. Specific nutrient abnormalities in asymptomatic HIV-1 infection. AIDS, 6: 701-708.

Montaner, J.S., Reiss, P., Cooper, D., Vella, S., Harris, M., Conway, B. et al. 1998. A randomized, double-blind trial comparing combinations of nevirapine, didanosine, and zidovudine for HIV-infected patients: the INCAS Trial. Italy, Netherlands, Canada and Australia Study. JAMA, 279: 930-7.

Walensky, R.P., Paltiel, A.D., Losina, E., Mercincavage, L.M., Schackman, B.R., Sax, P.E., et al. 2006. The survival benefits of AIDS treatment in the United States. J. Infect. Dis., 194: $11-19$.

Wester, C.W., Koethe, J.R., Shepherd, B.E., Stinnette, S.E., Rebeiro, P.F., Kipp, A.M., et al. 2011. Non-AIDS-defining events among HIV-1-infected adults receiving combination antiretroviral therapy in resource-replete versus resource-limited urban setting. AIDS, 25(12): 1471-1479.

Panel on Antiretroviral Guidelines for Adults and Adolescents: Guidelines for the use of antiretroviral agents in HIV-1-infected adults and adolescents. Department of Health and Human Services.

Hasse, B., Ledergerber, B., Furrer, H., Battegay, M., Hirschel, B., Cavassini, M., et al. 2011. Swiss HIV Cohort Study. Morbidity and aging in HIVinfected persons: the Swiss HIV cohort study. Clin. Infect. Dis., 53(11): 113-9.

The Antiretroviral Therapy Cohort Collaboration (ART-CC writing committee). Causes of death inHIV-1infected patients treated with antiretroviral therapy, 1996-2006: collaborative analysis of $13 \mathrm{HIV}$ cohort studies. Clin. Infect. Dis., 50: 13871396.

United Nations Children's Fund (UNICEF). State of the World's Children 2009.

World Bank. Nutrition at a glance- Nigeria.

Jiang, S., He, J., Zhao, X., Li, H. 2012. The effect of multiple micro nutrient supplementation on mortality and morbidity of HIV infected Adults: A Meta-analysis of RCT. J. Nutr. Sci. Vitaminol., 58: 105-112.

Keusch, G.T., Farthing, M.J. 1990. Nutritional aspects of AIDS. Аnnu. Rev. Nutr., 10: 475-501.

Raiten, D.J., Grinspoon, S., Arpadi, S. 2005. Nutritional considerations in the use of ART in resource-limited settings. Geneva, Switzerland: WHO, 2005.

Henrik Friis. 2005. Micronutrients and HIV infection: a review of current evidence. Consultation on Nutrition and HIV/AIDS in Africa: Evidence, lessons and recommendations for action Durban, South Africa10-13 April 2005.

Baum, M.K., Campa, A., Lai, S., Sales Martinez, S., Tsalaile, L., Burns, P., et al. 2013. Effect of micronutrient supplementation on disease 
progression in asymptomatic, antiretroviral-naïve, $\quad \mathrm{HIV}$-infected adults in Botswana: a randomized clinical trial. JAMA, 310(20): 215463.

Drain, P.K., Kupka, R., Mugusi, F., Fawzi, W.W. Micronutrients in HIV positive persons receiving highly active antiretroviral therapy. Am. J. Clin. Nutr., 85(2): 333-345.

Iwu, A.C., Duru, C.B., Uwakwe, K.A., Obionu, C.N., Diwe, K.C., Abah, S.O., et al. 2016. Effect of Multiple Micronutrient Supplementation on CD4 T Cell levels of Clinically Stable HIV patients on Highly Active Antiretroviral Therapy; A Randomized Control Crossover Trial. Amer. J. Clin. Med. Res., 4(1): 1-6.

Wellek, S., Blettner, M. 2012. On the proper use of the crossover design in clinical trials. Dtsch Arztebl Int., 109(15): 276-281.

Friis, H., Michaelsen, K.F. 1998. Micronutrients in HIV infection: a review. Euro. J. Clin. Nutrition, 52: 157-163.
Amorosa, V., Synnestvedt, M., Gross, R., Friedman, H., MacGregor, R.R., Gudonis, D., et al. 2005. A Tale of 2 Epidemics: The Intersection Between Obesity and HIV Infection in Philadelphia. JAIDS J. Acquired Immune Deficiency Syndromes, 39(5): 557-61.

Riddler, S.A., Smit, E., Cole, S.R., Li, R., Chmiel, J.S., Dobs, A., et al. 2003. Impact of HIV infection and HAART on serum lipids in men. JAMA. 289(22): 2978-82.

Lucien, K.F.H., Clement, A.N.J., Fon, N.P., Weledji, P., Ndikvu, C.P. 2010. The Effects of Antiretroviral Treatment on Liver function enzymes among HIV infected outpatients attending the Central hospital of Yaounde Cameroon. Afr. J. Clin. Exper. Microbiol. FR. 11(3): 174-178.

Alo, M.N., Okonkwo, E.C., Onyebuchi, A.K., Anyim, C.,. Agah, M.V. 2012. Assessment of the Effects of Highly Active Antiretroviral Therapy on the Renal Function of Patients with HIV-1 in a Rural Setting of South Eastern Nigeria. J. Natural Sci. Res., 2:7.

\section{How to cite this article:}

Anthony C. Iwu, Kenechi A. Uwakw, Chukwuma B. Dur, Kevin C. Diwe, Irene A. Meren, Abah O. Steve, Christopher N. Obionu, Nathan C. Nwaimo, Uche R. Oluoha, Ikechi Ohanle and Emmanuel U. Ndukwu. 2016. Multiple Micronutrient Supplementation Effect on Vital Metabolic parameters of Stable HIV Patients on Long term Highly Active Antiretroviral Therapy; A Randomized Crossover Trial. Int.J.Curr.Microbiol.App.Sci. 5(3): 776-786. doi: http://dx.doi.org/10.20546/ijcmas.2016.503.090 